\title{
Efeito do pó de resíduo cerâmico como adição ativa para o concreto
}

\author{
The effect of ceramic waste powder as active addition for
} concrete

\section{Angela Teresa Costa Sales \\ Ricardo dos Santos Alferes Filho}

\section{Resumo}

$\mathbf{E}$

ste trabalho estuda a utilização de pó de resíduo de cerâmica em substituição parcial ao cimento Portland na produção de concretos. $\mathrm{Na}$ análise da atividade pozolânica desse material, o ensaio com argamassa de cimento resultou em um índice de 76,9\%. Para avaliar o comportamento do concreto, foram produzidas misturas com substituição de $10 \%$, $20 \%$ e $40 \%$ do cimento pela adição de pó de resíduo cerâmico. Ensaios de resistência mecânica à compressão mostraram que, aos 28 dias, houve redução de $11 \%$ dessa propriedade para a substituição de $10 \%$ do cimento; houve aumento de $11 \%$ para a substituição de $20 \%$ do cimento; e $17 \%$ de redução para a substituição de $40 \%$ do cimento. O módulo de elasticidade dos concretos não sofreu significativas variações, registrando-se apenas um aumento de $8 \%$ para o concreto com $20 \%$ de adição. Não houve grandes variações nos índices físicos com a introdução da adição ao concreto. Pode-se concluir que a substituição do cimento por adição de pó cerâmico, nos teores estudados, não causou significativa redução da resistência mecânica, rigidez e compacidade nos concretos estudados, indicando a viabilidade de sua aplicação em concretos, com vantagens relacionadas à preservação ambiental, pela incorporação do resíduo cerâmico.

Palavras-chave: Pó de resíduo cerâmico. Adições pozolânicas. Concreto de cimento Portland.

Angela Teresa Costa Sales Universidade Federal de Sergipe São Cristovão - SE - Brasil

Ricardo dos Santos Alferes Filho

Universidade Federal de Sergipe São Cristovão - SE - Brasil

Recebido em 29/10/12 Aceito em 18/11/13

\section{Abstract}

This paper investigates the use of ceramic waste powder in the partial replacement of Portland cement to produce concretes. The analysis of the pozzolanic activity of this mineral admixture resulted in an index of $76.9 \%$. In order to study the behavior of the concrete, mixtures with 10\%, $20 \%$ and $40 \%$ of cement replacement content were prepared. Compressive tests have shown an $11 \%$ strength reduction for the $10 \%$ replacement concrete, an 11\% strength increase for the $20 \%$ replacement concrete and a $17 \%$ strength reduction for the $40 \%$ replacement concrete. Elastic modulus tests of the concrete mixtures have not shown any considerable variations, with an increase of just $8 \%$ for the concrete with $20 \%$ mineral admixture content. Minor variations in the physical properties of the concrete were observed with the introduction of the admixture. The concl; usion was made that the partial replacement of cement by the ceramic powder admixture at the levels studied caused no significant reduction in mechanical strength, stiffness or porosity in the concrete mixtures.

Keywords: Ceramic waste powder. Pozzolanic mineral admixture. Portland cement concrete. 


\section{Introdução}

O crescimento de diversos setores da economia, principalmente o industrial, trouxe o incremento da geração de resíduos resultantes dos processos de produção. É crescente a preocupação de muitos setores da sociedade com a disposição final desses resíduos, pois, com muita frequência, não tem sido regida por princípios de preservação ambiental. Nota-se a tendência a que as empresas incorporem a questão ambiental na tomada de decisões, visando preservar sua imagem como corporação ambientalmente responsável, ou somente garantir o cumprimento de regulamentações governamentais.

Outra questão ambiental urgente está relacionada à proteção dos recursos naturais não renováveis. Com o aumento desenfreado da produção, a demanda por insumos básicos tem levado a níveis extremos de exploração dos recursos naturais, notadamente as matérias-primas minerais. Prevê-se que prevalecerá a importância das rochas e dos minerais industriais (RMIs), também chamados de minerais não metálicos, nos usos tradicionais, como construção civil, que exigirão grandes volumes de matérias-primas para atender à demanda reprimida por produtos para populações ainda em crescimento.

\section{As matérias-primas para construção civil constituem o grupo mineral que mais é extraído em volume. O setor de construção é de longe o setor industrial que mais consome RMIs em quantidade, principalmente pelos agregados [...] (LINS, 2005).}

A indústria cerâmica é fornecedora de componentes essenciais para vários setores produtivos, sendo a indústria da construção civil um dos maiores consumidores. Materiais cerâmicos estão presentes nas construções, sob a forma de blocos, tijolos, lajotas, telhas, placas de revestimento, tubos, etc. Esse tipo de indústria gera resíduos em quantidades que variam de acordo com os métodos de produção. No caso da cerâmica vermelha, os resíduos são, geralmente, fragmentos de blocos, tijolos, telhas e lajotas, gerados pela quebra dos elementos, seja na etapa da queima, seja no transporte.

Sabe-se que a indústria da construção civil, e a cadeia produtiva que lhe dá suporte, é uma das maiores entre os setores da economia mundial e gera impactos ambientais bastante importantes. É voraz consumidora de matérias-primas, em sua maioria proveniente de recursos naturais não renováveis, gera volumes consideráveis de resíduos, seja na fase de construção, com perdas e desperdícios de materiais, seja na poluição ambiental provocada por disposição inadequada de resíduos de demolição após o fim da vida útil da construção. Segundo John (2000), a cadeia produtiva da construção civil apresenta características que a credenciam a ser grande recicladora, contribuindo para a redução de impactos ambientais. Entre os fatores promotores dessa vocação para a reciclagem, é destacado que muitos componentes para a construção são de produção simples, a exemplo dos compostos por agregados e aglomerantes minerais, não havendo exigências muito rígidas de características como esterilidade e pureza elevada, o que simplifica o processo.

Levantamento feito com os ceramistas dos municípios de Ituiutaba e Monte Carmelo, no Triângulo Mineiro (Minas Gerais), resultou em um percentual de quebra do produto que alcançou $15 \%$ da produção total (DIAS, 2004). Além disso, esse estudo indicou, como percentual mínimo possível de geração de resíduos, nessas indústrias, o valor aproximado de 3\%. Senthanarai e Manoharan (2005) consideram que, na indústria cerâmica, cerca de $30 \%$ da produção é descartada com resíduo. Embora haja muitas variáveis envolvidas numa estimativa de geração de resíduos desse setor, percebe-se que essa quantidade é significativa, pois grandes volumes desses resíduos costumam ficar acumulados nos arredores das instalações das fábricas.

Em pesquisa realizada no estado do Rio de Janeiro, em 2004, a pedido da Associação Nacional da Indústria Cerâmica (Anicer), em parceria com o Sindicato da Indústria da Cerâmica Vermelha (Sindicer-RJ), Serviço Brasileiro de Apoio às Micro e Pequenas Empresas (Sebrae) e Serviço Nacional de Aprendizagem Industrial (Senai), grande parte dos representantes das indústrias de cerâmica vermelha afirmou que o percentual aproximado de perdas no processo produtivo é inferior a $10 \%$. O baixo nível de perdas registradas pode se dever à falta de registro por parte das indústrias, pois apenas $27,59 \%$ das empresas pesquisadas realizam controle das perdas nas etapas de produção da cerâmica (ASSOCIAÇÃO..., 2005a).

Segundo Vieira, Souza e Monteiro (2004), a fabricação de cerâmica vermelha no Polo de Campos dos Goytacazes, no estado do Rio de Janeiro, apesar das variações em função da época do ano e das conjunturas de mercado, correspondia a cerca de 70 milhões de peças por mês. Dessa produção, aproximadamente $90 \%$ se referiam a blocos cerâmicos de vedação. Segundo os autores, as indústrias com melhor controle de qualidade

114 Sales, A. T. C.; Alferes Filho, R. dos S. 
apresentavam perdas, na etapa da queima, entre $0,5 \%$ e $1,0 \%$, enquanto havia indústrias que chegavam a apresentar $10 \%$ de perda. Pode-se concluir que o número de peças refugadas variava de 350.000 a 7.000.000, mensalmente.

O reaproveitamento desses resíduos, por reutilização, em aterros, ou por reciclagem, constitui-se numa alternativa benéfica em vários aspectos. Entre as vantagens, estariam a redução de áreas de deposição dos resíduos e a economia advinda da utilização desses resíduos para compor materiais de construção de menor custo. Os resíduos de cerâmica vermelha, desde que bem armazenados, têm a vantagem, sobre os resíduos de construção e demolição (RCD), de ser mais homogêneos em sua composição.

A reciclagem desses resíduos pode ser considerada sob duas vertentes de grande interesse do ponto de vista da construção civil: a reciclagem dos resíduos para geração de agregados para concretos e argamassas; e a produção do pó de cerâmica vermelha moída, que, uma vez dotado de atividade pozolânica, pode se constituir numa adição ativa para concretos e argamassas, e substituir parcialmente o aglomerante (cimento ou cal) nessas misturas.

O presente estudo buscou analisar propriedades físicas e mecânicas de concretos com adição de pó de resíduo cerâmico moído, verificando sua atuação como adição ativa. Estudou-se o resíduo cerâmico moído, em substituição parcial do cimento Portland, visando à melhoria de propriedades dessas misturas cimentícias.

\section{Adições para o concreto}

Cavalcanti (2006) classifica as adições minerais em predominantemente inertes (API) e predominantemente reativas (APR), baseando-se na possibilidade de haver função aglomerante potencial ou não. As APR podem ser materiais pozolânicos, a exemplo das cinzas volantes, cinzas de casca de arroz, cinzas da queima do bagaço da cana de açúcar, sílica ativa e metacaulim.

Materiais pozolânicos são substâncias naturais ou pozolanas industriais, silicosos ou silicoaluminosos, ou uma combinação destes. Não endurecem por si próprios quando misturados com água, mas obtêm essa propriedade ao reagir, em temperatura ambiente, com hidróxido de cálcio dissolvido, para formar compostos de silicatos de cálcio e aluminatos de cálcio, que desenvolvem resistência mecânica. Esses compostos são similares àqueles que são formados no endurecimento de cimentos hidráulicos (JACKSON, 2004). Adições pozolânicas podem substituir parcialmente o cimento Portland, numa mistura cimentícia.

As API têm a ação física de promover maior compacidade e refinamento de poros do concreto, aumentando a densidade e preenchendo vazios. Tem-se como exemplos os pós finos de calcário, quartzo e resíduos de serragem de mármore e granito. Essas adições são incorporadas ao concreto em substituição ao agregado miúdo e, sendo mais finas, dão coesão à mistura (TUTIKIAN; DAL MOLIN, 2008).

A norma NBR 12653 (ABNT 1992a) classifica as adições pozolânicas em naturais ou artificiais. As pozolanas naturais podem ser de origem vulcânica, geralmente de caráter petrográfico ácido, ou de origem sedimentar. Já as pozolanas artificiais são materiais originados de tratamento térmico ou como subprodutos industriais, como as argilas calcinadas, cinzas volantes, cinzas de resíduos vegetais, etc. Essa norma classifica as adições pozolânicas nas classes N, C e E. As adições da classe $\mathrm{N}$ são oriundas de materiais vulcânicos de caráter petrográfico ácido, cherts silicosos, terras diatomáceas e argilas calcinadas. As da classe C são as cinzas volantes, resultantes da queima do carvão mineral em usinas termoelétricas; e as da classe E são quaisquer pozolanas que difiram das classes anteriores.

Há de se considerar o benefício ambiental da aplicação dos pós inertes em concretos e argamassas, quando esses provêm de resíduos ou subprodutos industriais. Alguns tipos de resíduos têm determinada composição química, ou estado vítreo, que lhes conferem reatividade em meio aquoso, resultando em endurecimento, podendo ser utilizados como parte do aglomerante.

\section{Resíduos da indústria cerâmica como adição a misturas cimentícias}

Estudos anteriores que trataram de resíduos da indústria cerâmica obtiveram resultados que mostram que o resíduo de cerâmica vermelha moída, quando adicionado ao concreto, apresenta propriedades pozolânicas.

Desir et al. (2005), em sua pesquisa, adicionaram resíduo de tijolo moído ao concreto, em teores de $15 \%$ e $50 \%$, como também adicionaram resíduos de corte de rocha, que não possuem atividade pozolânica. Resultados de ensaios com o resíduo de tijolo moído apontaram propriedades pozolânicas, que se confirmaram na curva de evolução de resistência no tempo, a qual apontava um aumento de resistência de pelo menos $15 \%$ em 
relação ao concreto com adição de material fino, mas sem propriedade pozolânica.

Carneiro, Moura e Leite (2009) obtiveram resultados semelhantes ao adicionar resíduos moídos de material cerâmico como substituição parcial ao cimento na produção de argamassas. Foram utilizados teores de $10 \%$ e $20 \%$ de substituição, tendo a argamassa com menor teor de substituição apresentado um ganho de resistência da ordem de $19 \%$, enquanto a argamassa de maior teor de substituição apresentou um decréscimo de $5 \%$ na resistência mecânica. Após a análise do difratograma de raios $\mathrm{X}$, concluiu-se pela característica possivelmente reativa da amostra de material cerâmico.

Pereira-de-Oliveira, Castro-Gomes e Santos (2012) também estudaram a possibilidade de inserção de resíduos de cerâmica vermelha, tijolos e telhas, em substituição parcial do cimento, em concretos e argamassas. O pó fino obtido foi caracterizado em sua densidade, finura Blaine e morfologia das partículas, por microscopia eletrônica de varredura. O índice de atividade pozolânica foi determinado por ensaios em argamassa com diferentes teores de substituição do aglomerante, no intervalo de $0 \%$ a $40 \%$. Os resultados dos ensaios de resistência à compressão mostraram redução dessa propriedade com o aumento do teor de substituição do cimento por pó cerâmico, tanto para o obtido por moagem de telhas como para o obtido a partir de tijolos. Os autores consideraram que os resultados registrados confirmavam a atividade pozolânica do resíduo, viabilizando sua incorporação em argamassas e concretos.

Heikal, Zohdy e Abdelkreem (2013) utilizaram pó de tijolo cerâmico na produção de concreto autoadensável, analisando o comportamento reológico, físico-mecânico e a microestrutura da pasta de cimento e dos concretos, com teor de materiais cimentícios de $400 \mathrm{~kg}$ por metro cúbico de concreto fresco. O cimento foi substituído pelo pó de tijolo nos teores de 0, 50, 100 e $150 \mathrm{~kg} / \mathrm{m}^{3}$. A resistência à compressão do concreto diminuiu com o aumento do teor de pó de tijolo na ausência de aditivo para o concreto autoadensável, mas houve aumento de resistência quando os concretos continham aditivo. $\mathrm{O}$ aumento do teor de pó de tijolo até $250 \mathrm{~kg} / \mathrm{m}^{3}$ causou aumento da resistência à compressão do concreto. Os autores concluíram pela recomendação da aplicação do pó de tijolo cerâmico em concreto autoadensável com teores entre $30 \%$ e $40 \%$ de substituição do cimento.

\section{Procedimento experimental}

\section{Materiais utilizados}

O cimento utilizado foi do tipo CP II Z-32, marca Poty, com índice de finura de $1,70 \%$, medido segundo a norma NBR 11579 (ABNT, 1991), e tempo de início de pega de 2h20min, medido segundo a norma NBR NM 65 (ABNT, 2003a). Foi determinada a massa específica real do cimento seguindo-se a norma NBR NM 23 (ABNT, 2000), resultando em 3,02 $\mathrm{g} / \mathrm{cm}^{3}$. Os agregados utilizados na produção do concreto foram areia de cava, brita 0 e brita 1 , essas últimas de origem granítica. As características obtidas em ensaios com esses agregados são mostradas na Tabela 1.

A adição utilizada em substituição parcial ao cimento Portland para a qual se avaliou a atividade pozolânica foi o pó obtido da trituração e peneiramento de resíduos de cerâmica vermelha, mais especificamente blocos de vedação. Segundo informação do proprietário da indústria que forneceu os resíduos, o percentual de perdas na fábrica, em massa, corresponde a 1,6\%.

Os resíduos cerâmicos foram moídos em um triturador mecânico, cuja abertura das mandíbulas foi minimizada, de modo a ser obter uma granulometria em que prevalecesse a presença de pó, com grãos menores que $75 \mu \mathrm{m}$. O material obtido foi peneirado na peneira de abertura de 75 $\mu \mathrm{m}$, desprezando-se o material retido nessa peneira. Os teores de substituição do aglomerante por essa adição nos concretos foram fixados em $10 \%, 20 \%$ e $40 \%$.

Tabela 1 - Características físicas dos agregados utilizados

\begin{tabular}{c|c|c|c}
\hline Agregados & Características & Resultados & Normalização \\
\hline \multirow{3}{*}{ Areia } & Massa específica real (g/cm $\left.{ }^{3}\right)$ & 2,62 & \multirow{2}{*}{ NBR NM 52 (ABNT, 2009a) } \\
\cline { 2 - 4 } & Diâmetro máximo (mm) & 4,8 & \multirow{2}{*}{ NBR NM 248 (ABNT, 2003b) } \\
\cline { 2 - 4 } & Módulo de finura (\%) & 1,97 & \\
\hline \multirow{3}{*}{ Brita 0 } & Massa específica real (g/cm $\left.{ }^{3}\right)$ & 2,65 & \multirow{2}{*}{ NBR NM 53 (ABNT, 2009b) } \\
\cline { 2 - 4 } & Diâmetro máximo (mm) & 9,5 & \multirow{2}{*}{ NBR NM 248 (ABNT, 2003b) } \\
\cline { 2 - 4 } & Módulo de finura (\%) & 5,73 & \multirow{2}{*}{ NBR NM 53 (ABNT, 2009b) } \\
\hline \multirow{3}{*}{ Brita 1 } & Massa específica real (g/cm $\left.{ }^{3}\right)$ & 2,72 & \multirow{2}{*}{ NBR NM 248 (ABNT, 2003b) } \\
\cline { 2 - 4 } & Diâmetro máximo (mm) & 19,0 & \\
\cline { 2 - 4 } & Módulo de finura (\%) & 6,64 & \\
\hline
\end{tabular}

116 Sales, A. T. C.; Alferes Filho, R. dos S. 
O pó de resíduo cerâmico foi caracterizado química e microestruturalmente. Uma amostra do material foi submetida a ensaios de difração de raios $X \quad(D R X)$, em difratômetro Rigaku DMAX100, e por fluorescência de raios X (FRX), em equipamento da marca Bruker, modelo S8 TIGER, que, em conjunto, permitiram a identificação e a quantificação dos compostos e das fases cristalinas.

A análise por FRX (Tabela 2) de ensaio com duas amostras do pó de resíduo cerâmico mostrou que as maiores concentrações de óxidos foram para a sílica $\left(\mathrm{SiO}_{2}\right.$, em média de $\left.56,25 \%\right)$ e para a alumina $\left(\mathrm{Al}_{2} \mathrm{O}_{3}, \quad\right.$ com $\left.15,32 \%\right)$, juntas correspondendo a $71,57 \%$ do total.

De acordo com a norma NBR 12653 (ABNT, 1992a), para materiais pozolânicos da classe $\mathrm{N}$, como é classificada a adição investigada neste trabalho, o somatório dos percentuais de sílica, alumina e óxido de ferro deve ser de, no mínimo, $70 \%$. Como, para as amostras estudadas, a soma dos teores desses compostos já resulta em 76,76\%, tem-se que a exigência da norma foi atendida.

A Figura 1 apresenta os resultados da análise mineralógica por difração de raios X (DRX), obtidos para o pó de resíduo cerâmico, mostrando a predominância de quartzo e caulinita, com maiores picos.

A análise por difração de raios X (Figura 1) mostrou a presença, em maior escala, de quartzo $\left(\mathrm{SiO}_{2}\right)$ nas amostras. Deve-se considerar que a atividade pozolânica está relacionada com a presença de alumina e sílica predominantemente amorfas, que não podem ser detectadas na amostra do pó por esse ensaio.

Buscando-se dados acerca da magnitude da presença de sílica amorfa no pó cerâmico, aplicouse difração de raios $\mathrm{X}$, utilizando-se uma amostra de referência composta de quartzo cristalino puro. Determinaram-se as áreas atribuídas aos picos de difração da fase cristalina do quartzo em ambas as amostras, de pó cerâmico e de quartzo puro (Figura 2). Essa razão ficou em torno de $30 \%$, indicando que há, no máximo, $30 \%$ de quartzo na forma cristalina. Pode-se, então, concluir que os $70 \%$ restantes desse material encontram-se na forma de uma mistura de material amorfo e de segundas fases.

O pó de resíduo cerâmico teve determinada sua finura por meio da peneira $n^{\circ} 325$, com abertura de malha de $44 \mu \mathrm{m}$, segundo a NBR 9202 (ABNT, 1985), resultando num índice de finura de 7,5\%. Segundo a NBR 12653 (ABNT, 1992a), o teor máximo de material retido nessa peneira, para todas as classes de material pozolânico, é de $34 \%$. Assim, o material pozolânico estudado neste trabalho atende a esse padrão. Foi, ainda, determinada sua massa específica real, segundo a norma NM 23 (ABNT, 2000), resultando em um valor médio de $2,61 \mathrm{~g} / \mathrm{cm}^{3}$.

Foi utilizado o aditivo superplastificante Viscocrete Precast, da marca Sika, para adequar a trabalhabilidade das misturas ao abatimento do tronco de cone estabelecido.

Tabela 2 - Composição do pó de resíduo cerâmico em óxidos, por FRX

\begin{tabular}{cc}
\hline Fórmula & Concentração \\
\hline $\mathrm{SiO}_{2}$ & $56,25 \%$ \\
$\mathrm{Al}_{2} \mathrm{O}_{3}$ & $15,32 \%$ \\
$\mathrm{Fe}_{2} \mathrm{O}_{3}$ & $5,19 \%$ \\
$\mathrm{~K}_{2} \mathrm{O}$ & $1,90 \%$ \\
$\mathrm{MgO}$ & $1,08 \%$ \\
$\mathrm{TiO}_{2}$ & $0,76 \%$ \\
$\mathrm{Na}_{2} \mathrm{O}$ & $0,64 \%$ \\
$\mathrm{CaO}$ & $0,62 \%$ \\
$\mathrm{SO}_{3}$ & $0,20 \%$ \\
$\mathrm{BaO}$ & $0,09 \%$ \\
$\mathrm{ZrO}$ & $0,04 \%$ \\
$\mathrm{Cl}$ & $0,03 \%$ \\
$\mathrm{P}_{2} \mathrm{O}_{5}$ & $0,03 \%$ \\
$\mathrm{Cr}_{2} \mathrm{O}_{3}$ & $0,03 \%$ \\
$\mathrm{MnO}$ & $0,02 \%$ \\
$\mathrm{SrO}$ & $0,01 \%$ \\
\hline
\end{tabular}


Figura 1 - Identificação das fases cristalinas do pó de resíduo de cerâmica por DRX

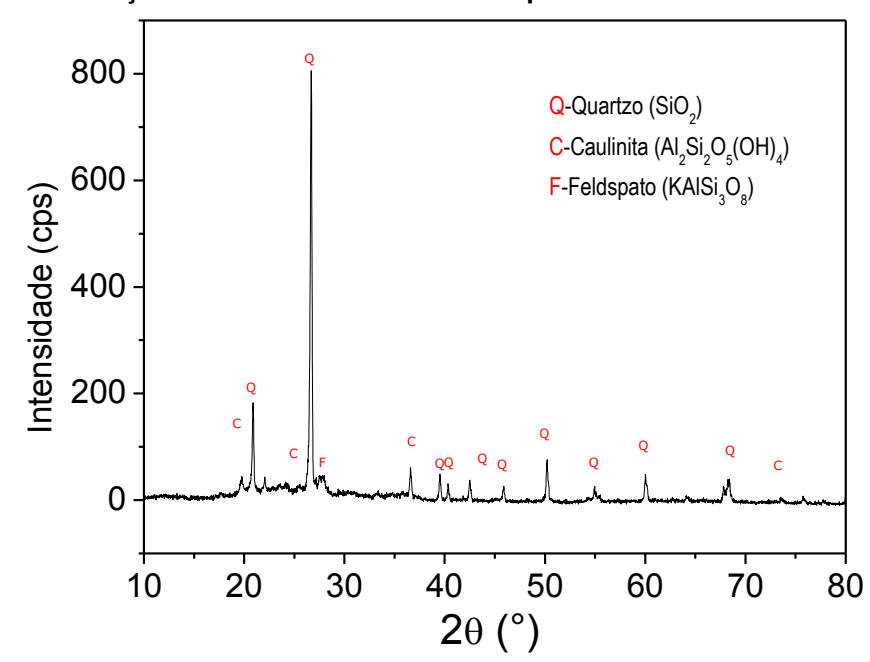

Figura 2 - Difratogramas do pó cerâmico e da amostra de referência

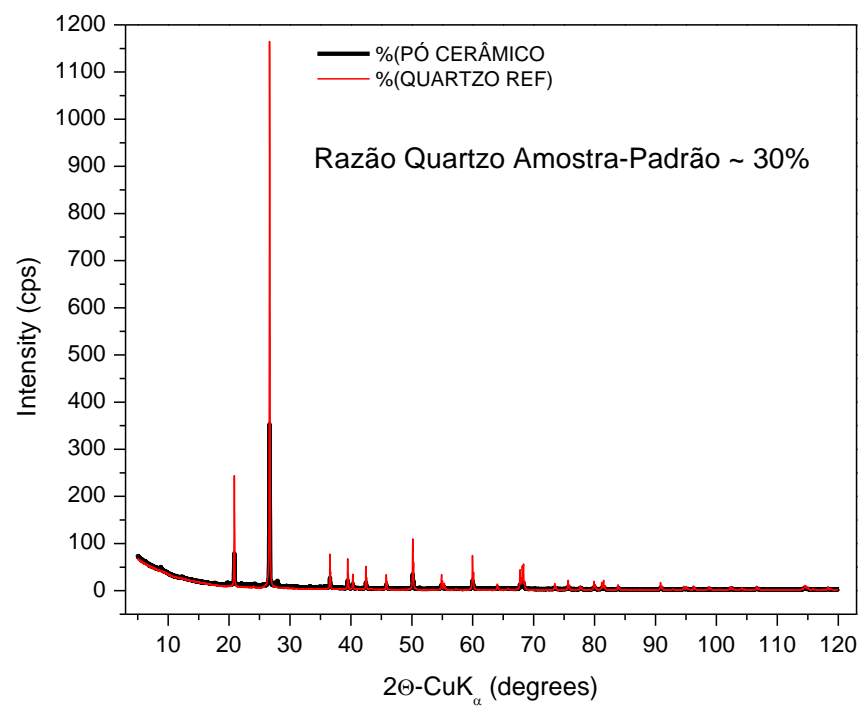

\section{Métodos}

\section{Determinação da atividade pozolânica}

Para determinação da atividade pozolânica do pó de resíduo cerâmico, foi seguido o procedimento descrito na NBR 5752 (ABNT, 1992b), que consiste na moldagem de seis corpos de prova de argamassa com aglomerante de cimento Portland. Os corpos de prova moldados foram divididos em dois grupos, um sem a adição cerâmica (Argamassa A) e o outro com adição (Argamassa B), em substituição ao cimento. $\mathrm{O}$ pó cerâmico foi seco em estufa a $110^{\circ} \mathrm{C}$, até a constância de massa, sem passar por qualquer outro beneficiamento, e deixado ao ar, no laboratório, para esfriar. A proporção de material pozolânico (pó de resíduo cerâmico) na argamassa do segundo grupo de corpos de prova foi de $35 \%$ do volume absoluto de cimento. Segundo a norma citada, as quantidades necessárias de água para produzir as argamassas, tanto do primeiro como do segundo grupo, deveriam corresponder aos índices de consistência de $225 \pm 5 \mathrm{~mm}$, determinados de acordo com a NBR 7215 (ABNT, 1997). Dessa forma, foram produzidas as misturas de argamassa, resultando nas composições constantes da Tabela 3.

Moldados os corpos de prova de argamassa, procedeu-se à ruptura deles, após cura submersa em água por 28 dias, obtendo-se os valores médios de resistência apresentados para os corpos de prova de referência e para aqueles com substituição parcial do cimento pela adição.

O índice de atividade pozolânica da adição foi obtido através da Equação 1:

$\frac{f_{C B}}{f_{C A}} .100(\%)$

Eq. 1 
Onde:

$\mathrm{f}_{\mathrm{CB}}$ - resistência média dos corpos de prova com cimento e material pozolânico; e

$\mathrm{f}_{\mathrm{CA}}$ - resistência média dos corpos de prova moldados apenas com cimento.

A quantidade de água requerida para obtenção de índices de consistência normais, de $225 \pm 5 \mathrm{~mm}$, para as argamassas, foi calculada pela Equação 2:

$\frac{B}{A} .100(\%)$

Eq. 2

Onde:

B e A - quantidades de água necessárias para a obtenção dos índices de consistências requeridos para as argamassas B e A respectivamente.

\section{Ensaios mecânicos com os concretos}

Para a determinação das propriedades mecânicas dos concretos com adição do pó cerâmico, procedeu-se à moldagem de corpos de prova em moldes cilíndricos de $200 \mathrm{~mm}$ de altura e $100 \mathrm{~mm}$ de diâmetro. Foram estabelecidos três traços com valores diferentes de adição a ser utilizada em substituição ao cimento, e um traço sem adição, denominado mistura de referência, para comparação.

As misturas de concreto foram produzidas a partir de um traço mantido constante, em massa, de 1:1,56:0,81:1,88, de cimento, areia, brita 0 e brita 1. Dosaram-se os concretos a partir de uma resistência característica à compressão $\left(\mathrm{f}_{\mathrm{ck}}\right)$ de 30 $\mathrm{MPa}$, com relação água/cimento também mantida constante para todas as misturas, igual a 0,45 . O abatimento de tronco de cone estabelecido para as misturas foi de $80 \mathrm{~mm} \pm 10 \mathrm{~mm}$, medido segundo a norma NBR NM 67 (ABNT, 1998). A dosagem seguiu o método do ACI/ABCP (RODRIGUES, 1995).

A nomenclatura, os teores de substituição de cimento por pó cerâmico e o teor de aditivo superplastificante necessário para obter o abatimento desejado em cada traço estão descritos na Tabela 4 , a seguir.

Os corpos de prova foram retirados dos moldes, após $24 \mathrm{~h}$ de moldagem, e submetidos à cura submersa em água, até as idades de ruptura à compressão, que se deram aos 3,7 e 28 dias. As moldagens dos corpos de prova e os ensaios de ruptura foram realizados segundo as normas NBR 5738 (ABNT, 2003) e NBR 5739 (ABNT, 2007). Os ensaios de determinação dos módulos de elasticidade seguiram a norma NBR 8522 (ABNT, 2008). O ensaio de ruptura à compressão dos corpos de prova foi executado na máquina universal de ensaios modelo DL 20000, marca Emic.

\section{Ensaios físicos com os concretos}

Foram feitos ensaios de determinação da absorção de água, massas específicas e índices de vazios utilizando-se 2 corpos de prova para cada mistura, segundo a norma NBR 9778 (ABNT, 2005b). Esses corpos de prova foram deixados em estufa, a $100{ }^{\circ} \mathrm{C}$, por 3 dias, e foram determinadas suas massas secas. Em seguida, foram imersos em água, também por 3 dias e, após isso, passaram por processo de fervura (Figura 3), por 5 h, sendo, ao final, determinadas as massas imersas em água, em balança hidrostática, e massas saturadas após secagem superficial com pano seco. Foram determinadas as propriedades de absorção de água (A), índice de vazios $\left(\mathrm{I}_{\mathrm{v}}\right)$, massa específica da amostra seca $\left(\rho_{\mathrm{s}}\right)$, massa específica da amostra saturada $\left(\rho_{\text {sat }}\right)$ e massa específica real $\left(\rho_{\mathrm{r}}\right)$, cujos resultados foram obtidos, respectivamente, pelas Equações 3, 4, 5, 6 e 7, a seguir.

$$
\begin{aligned}
& A=\frac{m_{\text {sat }}-m_{s}}{m_{s}} \times 100 \\
& I_{v}=\frac{m_{s a t}-m_{s}}{m_{\text {sat }}-m_{i}} \times 100 \\
& \rho_{s}=\frac{m_{s}}{m_{s a t}-m_{i}} \\
& \rho_{\text {sat }}=\frac{m_{\text {sat }}}{m_{\text {sat }}-m_{i}} \\
& \rho_{r}=\frac{m_{s}}{m_{s}-m_{i}},
\end{aligned}
$$

Onde:

$\mathrm{m}_{\text {sat }}$ é a massa da amostra saturada em água após imersão e fervura;

$\mathrm{m}_{\mathrm{s}}$ é a massa da amostra seca em estufa;

$\mathrm{m}_{\mathrm{i}}$ é a massa da amostra saturada imersa em água após fervura.

Tabela 3 - Massa necessária de cada material para moldagem de três corpos de prova

\begin{tabular}{ccc}
\hline \multirow{2}{*}{ Material } & \multicolumn{2}{c}{ Massa necessária (g) } \\
\cline { 2 - 3 } & Argamassa A & Argamassa B \\
\hline Cimento & 312 & 202,8 \\
Adição & - & 91,17 \\
Areia & 936 & 936 \\
Água & 171,60 & 194,56 \\
\hline
\end{tabular}


Tabela 4 - Nomenclatura das misturas de concreto

\begin{tabular}{c|c|c}
\hline Mistura & Teor de substituição & Teor de aditivo \\
\hline PT00 & $0 \%$ & $0,38 \%$ \\
PT10 & $10 \%$ & $0,64 \%$ \\
PT20 & $20 \%$ & $0,77 \%$ \\
PT40 & $40 \%$ & $1,18 \%$ \\
\hline
\end{tabular}

Figura 3 - Ensaio de fervura dos corpos de prova

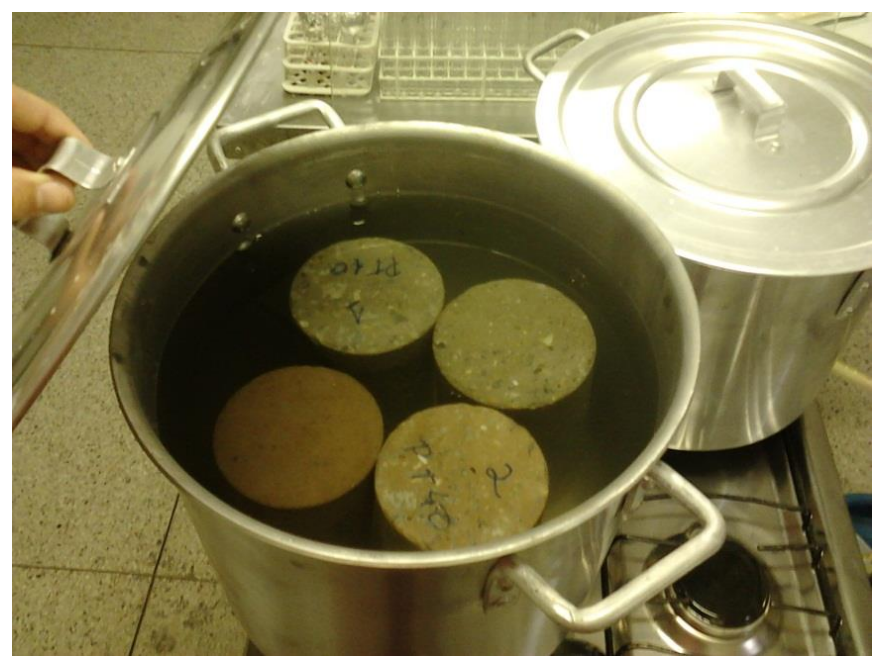

\section{Resultados e discussão}

\section{Atividade pozolânica do pó cerâmico}

Os resultados dos ensaios de determinação de resistência à compressão das argamassas com e sem substituição do cimento Portland por adição de pó cerâmico encontram-se na Tabela 5. Para a argamassa com substituição de $35 \%$ de cimento por pó cerâmico, a quantidade de água requerida para a obtenção do índice de consistência de 225 $\mathrm{mm} \pm 5 \mathrm{~mm}$ foi $13,38 \%$ superior à requerida para a argamassa somente com cimento Portland. Pode-se supor que essa maior exigência de água para uma mesma consistência tenha sido resultante da maior finura do pó cerâmico, cujos grãos passavam todos pela abertura de malha da peneira de $75 \mu \mathrm{m}$.

De acordo com os resultados obtidos, chegou-se ao índice de atividade pozolânica com cimento Portland correspondente a 76,9\%. Pode-se concluir que o pó cerâmico estudado apresentou alguma atividade pozolânica, uma vez que, se esse material fosse completamente inerte, a relação água/materiais cimentícios na argamassa B seria de 0,96, o que resultaria num material com menor resistência do que os 18,65 $\mathrm{MPa}$ medidos em ensaio para essa mistura, como mostra a Tabela 6 . Considerando a Lei de Abrams, que relaciona a resistência do concreto com a relação água/cimento, um concreto com relação de 0,96 , como seria a argamassa B se o pó cerâmico fosse completamente inerte, apresentaria uma resistência à compressão em torno de $10 \mathrm{MPa}$ (RODRIGUES, 1995). Em estudo de Martins Neto e Djanikian (1999), com argamassas dosadas em central e produzidas na própria obra, concluiu-se que a variação da resistência à compressão das argamassas estudadas, em função da relação água/cimento, foi bem característica, aproximando-se do comportamento do concreto.

\section{Propriedades mecânicas dos concretos}

\section{Resistência à compressão}

Os resultados obtidos nos ensaios de resistência à compressão estão apresentados na Tabela 6 e na Figura 4.

Pode-se observar que, em idade mais precoce, aos 3 dias, os concretos com substituição do cimento Portland por pó de resíduo cerâmico apresentaram resistências à compressão inferiores à da mistura de referência, havendo diminuição da resistência com o aumento do teor de substituição. Após 7 dias de idade, o concreto com $20 \%$ de substituição passa a ter uma evolução mais intensa do ganho de resistência, chegando a ultrapassar a resistência da mistura de referência aos 28 dias de idade. Mehta e Monteiro (2008) incluem o aumento da resistência 
final entre os prováveis benefícios a serem obtidos com o uso de adições minerais no concreto.

O concreto de referência apresentou média de resistência à compressão, aos 28 dias de idade, de $31,8 \mathrm{MPa}$, portanto $6 \%$ superior à resistência prevista na dosagem $\left(f_{c k}\right)$. Observou-se que, nessa idade, as substituições de $10 \%$ e $40 \%$ em massa do cimento Portland por pó de resíduo de cerâmica vermelha provocaram reduções de $11,4 \%$ e $16,9 \%$ da resistência à compressão respectivamente em relação à resistência do concreto de referência. Já para a mistura com $20 \%$ de substituição, observouse incremento dessa propriedade em $11,1 \%$. Desses resultados pode-se supor que, para os materiais utilizados neste estudo, o teor de $20 \%$ de substituição do cimento por pó cerâmico seria o considerado como ótimo, por promover a melhor combinação de efeito pozolânico e efeito fíler, sem tanto prejuízo à trabalhabilidade que exigisse maior dosagem do aditivo superplastificante.

$\mathrm{Na}$ mistura com $40 \%$ de substituição, foi percebida significativa perda de trabalhabilidade, chegandose a um teor de aditivo superplastificante próximo do limite máximo recomendado pelo fabricante. Considerando-se que a redução do custo do concreto, provocada pela substituição de $40 \%$ da massa de cimento por pó de resíduo de cerâmica vermelha seria significativa, além das vantagens ambientais provocadas pela redução de gasto de energia e de emissões de $\mathrm{CO}_{2}$ para a atmosfera, que advêm da produção do clínquer, pode-se considerar que a redução da resistência mecânica à compressão de cerca de $17 \%$ seria plenamente compensatória.

Tabela 5 - Resultados dos ensaios à compressão de argamassas

\begin{tabular}{ccc}
\hline \multirow{2}{*}{ Argamassa } & \multicolumn{2}{c}{ Resistência à compressão } \\
\cline { 2 - 3 } & Média (MPa) & Coeficiente de variação (\%) \\
\hline $\mathrm{A}$ & 24,26 & $13,97 \%$ \\
$\mathrm{~B}$ & 18,65 & $5,67 \%$ \\
\hline
\end{tabular}

Tabela 6 - Resultados dos ensaios de ruptura à compressão

\begin{tabular}{c|c|c|c|c|c|c}
\hline \multirow{3}{*}{ Mistura } & \multicolumn{9}{c}{ Resistência à compressão } \\
\cline { 2 - 7 } & \multicolumn{2}{|c|}{ 3 dias } & \multicolumn{2}{c}{ 7 dias } & \multicolumn{2}{c}{ 28 dias } \\
\cline { 2 - 7 } & $\begin{array}{c}\text { Média } \\
(\mathbf{M P a})\end{array}$ & $\begin{array}{c}\text { Coef. Var. } \\
(\boldsymbol{\%})\end{array}$ & $\begin{array}{c}\text { Média } \\
(\mathbf{M P a})\end{array}$ & $\begin{array}{c}\text { Coef. Var. } \\
(\boldsymbol{\%})\end{array}$ & $\begin{array}{c}\text { Média } \\
(\mathbf{M P a})\end{array}$ & $\begin{array}{c}\text { Coef. Var. } \\
(\boldsymbol{\%})\end{array}$ \\
\hline PT00 & 23,51 & 3,12 & 25,83 & 14,57 & 31,79 & 10,87 \\
PT10 & 21,97 & 13,68 & 25,78 & 13,77 & 28,17 & 10,48 \\
PT20 & 17,79 & 3,73 & 20,87 & 2,53 & 35,33 & 6,26 \\
PT40 & 14,72 & 9,57 & 17,54 & 8,43 & 26,42 & 3,99 \\
\hline
\end{tabular}

Figura 4 - Evolução do ganho de resistência dos concretos

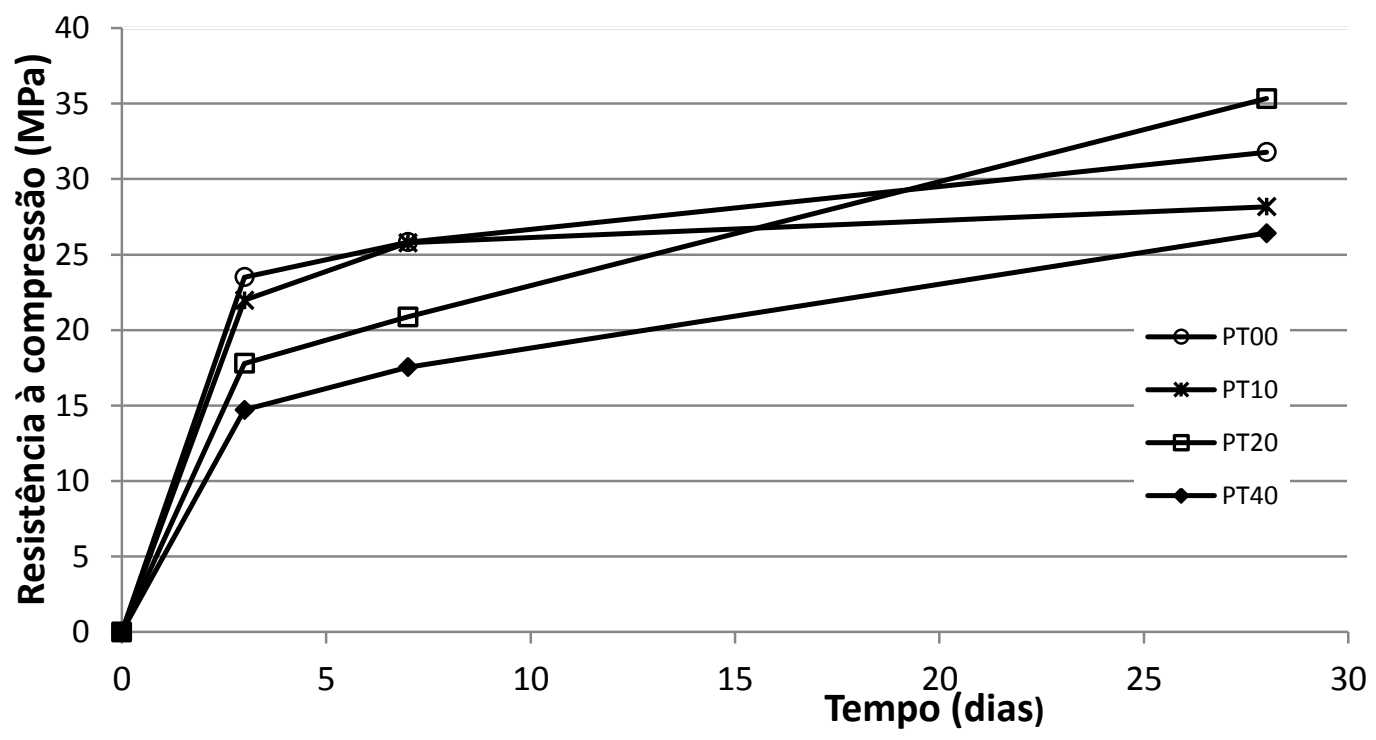


No estudo de Vieira (2005), usando concretos com substituições de $20 \%$ e $40 \%$ de cimento por pó de tijolo moído, houve redução de, aproximadamente, $11 \%$ da resistência à compressão para o teor de substituição de $40 \%$ aos 56 dias de idade. Para o concreto com $20 \%$ de substituição, essa redução foi de somente $5 \%$. Conforme observado, o teor de substituição de $20 \%$ do cimento Portland por resíduo de cerâmica vermelha tem-se mostrado como um valor mais favorável para dosagem.

\section{Módulo de elasticidade}

Com os dados obtidos no ensaio do módulo de elasticidade, elaborou-se a Tabela 7. Os resultados apresentados permitem observar que, comparado ao concreto de referência, há um discreto incremento de rigidez nas misturas, com $10 \%$ e $40 \%$ de adição $(0,19 \%$ e $2,26 \%$ respectivamente) substituindo o cimento. No entanto, a mistura com $20 \%$ de substituição do cimento por pó de resíduo cerâmico apresentou um módulo de elasticidade ligeiramente maior que os demais $(8,25 \%$ maior que o concreto de referência), valor coerente com o resultado de ruptura por compressão simples, que apresentou a mistura PT20 como a de maior resistência. Isso confirma a probabilidade da hipótese de esse teor de adição promover uma combinação mais satisfatória de efeitos pozolânico e fíler. No entanto, excetuando-se o valor de módulo de elasticidade para essa mistura, os demais valores obtidos para os concretos foram tão próximos que, praticamente, se pode afirmar que não houve significativa influência da adição do pó cerâmico sobre essa propriedade.

\section{Propriedades físicas}

A Tabela 8, a seguir, apresenta os valores obtidos para o ensaio de determinação de parâmetros relacionados à porosidade dos concretos estudados, que foram a absorção de água, índice de vazios e massas específicas seca, saturada e real.

Dos resultados, observa-se que as misturas com teores de $10 \%, 20 \%$ e $40 \%$ apresentaram valores de absorção bem próximos entre si e em relação ao apresentado pelo concreto de referência, variando em $-5,4 \%$, $+6,5 \%$ e $+0,8 \%$ respectivamente em relação a esse último. $\mathrm{O}$ comportamento físico das misturas manteve essa tendência quando analisado o índice de vazios obtido. Para as misturas de $10 \%$ e $40 \%$ de substituição, foram obtidos valores $5,6 \%$ e $0,4 \%$, respectivamente, inferiores ao concreto de referência, enquanto a mistura com $20 \%$ de adição apresentou um índice de vazios $2,9 \%$ superior ao do concreto de referência.

A massa específica seca apresentou resultados próximos entre si, sendo o maior o de $2,30 \mathrm{~g} / \mathrm{cm}^{3}$, relativo ao concreto de referência, e o menor o de $2,23 \mathrm{~g} / \mathrm{cm}^{3}$, referente à mistura com $20 \%$ de adição de pó cerâmico. Os valores de massa específica saturada mostraram um comportamento semelhante, com os valores situados entre os limites de $2,41 \mathrm{~g} / \mathrm{cm}^{3}$ e $2,35 \mathrm{~g} / \mathrm{cm}^{3}$, relativos às mesmas misturas citadas.

A massa específica real do concreto de referência apresentou a média de $2,58 \mathrm{~g} / \mathrm{cm}^{3}$, enquanto as misturas com adições apresentaram valores inferiores em $0,78 \%, 2,33 \%$ e $1,16 \%$ respectivamente, correspondentes às misturas PT10, PT20 e PT40. Os índices físicos das misturas de concreto indicam pequena variação no volume de vazios nos concretos para as misturas com adição, quando comparados ao concreto de referência.

Tabela 7 - Resultados dos ensaios de módulo de elasticidade

\begin{tabular}{ccc}
\hline Mistura & $\begin{array}{c}\text { Média do módulo de } \\
\text { elasticidade (Gpa) }\end{array}$ & $\begin{array}{c}\text { Comparação com o concreto } \\
\text { de referência }\end{array}$ \\
\hline PT00 & 31,04 & - \\
PT10 & 31,10 & $+0,19 \%$ \\
PT20 & 33,60 & $+8,25 \%$ \\
PT40 & 31,74 & $+2,26 \%$ \\
\hline
\end{tabular}

Tabela 8 - Índices físicos do concreto

\begin{tabular}{|c|c|c|c|c|c|}
\hline \multirow[b]{2}{*}{ Mistura } & \multicolumn{5}{|c|}{ Parâmetros de porosidade } \\
\hline & $\begin{array}{c}\text { Absorçãa } \\
(\%)\end{array}$ & $\begin{array}{c}\text { Índice de } \\
\text { vazios }(\%)\end{array}$ & $\begin{array}{c}\text { Massa específica seca } \\
\left(\mathrm{g} / \mathrm{cm}^{3}\right)\end{array}$ & $\begin{array}{l}\text { Massa específica } \\
\text { saturada }\left(\mathrm{g} / \mathrm{cm}^{3}\right)\end{array}$ & $\begin{array}{c}\text { Massa específica real } \\
\left(\mathrm{g} / \mathrm{cm}^{\mathbf{3}}\right)\end{array}$ \\
\hline PT00 & 4,79 & 11,00 & 2,30 & 2,41 & 2,58 \\
\hline PT10 & 4,53 & 10,38 & 2,29 & 2,40 & 2,56 \\
\hline PT20 & 5,10 & 11,32 & 2,23 & 2,35 & 2,52 \\
\hline PT40 & 4,83 & 10,96 & 2,27 & 2,38 & 2,55 \\
\hline
\end{tabular}

122 Sales, A. T. C.; Alferes Filho, R. dos S. 


\section{Conclusões}

Após a análise dos dados obtidos nos experimentos, foi possível chegar às conclusões que se seguem. A adição utilizada, oriunda da moagem e peneiramento de resíduos de cerâmica vermelha, apresentou-se, em ensaio de difratometria de raios $\mathrm{X}$, como composta predominantemente das fases cristalinas quartzo, caulinita e feldspato. Através de análise por fluorescência de raios $\mathrm{X}$ (FRX), foi obtida sua composição em termos de óxidos, com predominância de óxido de silício, em cerca de $56 \%$, e de trióxido de alumínio, com cerca de $15 \%$. Por difração de raios X, utilizando-se amostra de referência composta de quartzo cristalino puro, concluiu-se que havia no pó cerâmico, no máximo, $30 \%$ de quartzo na forma cristalina.

Essa adição apresentou índice de finura de 7,5\%, portanto inferior ao limite máximo para todas as classes de material pozolânico, que é de $34 \%$. A medida do índice de atividade pozolânica com cimento Portland, de acordo com a norma NBR 5752 (ABNT, 1992b), resultou em 76,9\%.

A análise do desempenho mecânico dos concretos à compressão, com adição de pó de resíduo cerâmico, mostrou que houve redução da resistência à compressão inicial, com o aumento do teor de substituição do cimento Portland pelo pó de resíduo cerâmico. Aos 28 dias de idade, houve pequena redução da resistência à compressão (cerca de $11 \%$ ) para o teor de substituição do cimento pela adição de $10 \%$; pequeno aumento (cerca de $11 \%$ ), para o teor de substituição de $20 \%$; e redução de cerca de $17 \%$, para o teor de substituição de $40 \%$. Apesar das influências das composições química e microestrutural do pó cerâmico, resultantes do tipo de matéria-prima usado e do processo de queima na produção do produto cerâmico, para o pó cerâmico utilizado neste trabalho, pode-se concluir que o teor de $20 \%$ de substituição foi o que melhor desempenho conferiu ao concreto.

Os ensaios de módulo de elasticidade mostraram muito pouca alteração dessa propriedade pela introdução da adição de pó cerâmico na mistura de concreto. A máxima variação observada foi o aumento de cerca de $8 \%$ do módulo de elasticidade para o concreto com $20 \%$ de adição, em relação ao concreto de referência.

Os índices físicos medidos para os concretos também não mostraram grandes variações na porosidade dos concretos com a introdução, no âmbito dos teores estudados, do pó cerâmico nas composições. Em relação à absorção de água, notou-se pequeno aumento para a mistura com
$20 \%$ de pó cerâmico, que foi de cerca de $6 \%$. Para a mistura com $10 \%$ de adição, foi observada uma redução da absorção de cerca de $5 \%$. Os índices de vazios permaneceram praticamente constantes para todas as misturas, o mesmo acontecendo para as massas específicas aparentes secas. As medidas de massa específica real também não sofreram significativas alterações.

Esses resultados levam a supor que a substituição de cimento Portland pelo resíduo de pó cerâmico não causou incremento significativo na porosidade das misturas endurecidas, o que leva à conclusão de que não haveria maiores problemas de durabilidade para as estruturas, causados pelo acesso de substâncias agressivas presentes no ambiente. Apesar disso, há de se considerar que a utilização da adição em substituição ao cimento leva a uma redução da alcalinidade do concreto, podendo resultar numa menor proteção química das armaduras, eventualmente presentes na estrutura, contra a corrosão.

O fato de as composições estudadas, contendo uma adição resultante do beneficiamento de um resíduo industrial, não terem sofrido relevantes prejuízos a seu desempenho mecânico e compacidade mostra as vantagens, em termos de preservação ambiental na indústria da construção civil, que podem ser auferidas quando houver dados científicos seguros em quantidade suficiente que possam embasar sua aplicação prática. Acrescenta-se ainda que, podendo-se utilizar teores bastante significativos de substituição do cimento pela adição, haveria vantagens em termos da redução da emissão de $\mathrm{CO}_{2}$ para a atmosfera, da qual a indústria cimentícia participa como importante setor poluente. Ainda, têm-se as vantagens de evitar, ou reduzir, a disposição inadequada dos resíduos cerâmicos em aterros, ou em áreas ainda menos apropriadas, e de reduzir a exploração de recursos não renováveis.

\section{Referências}

\section{ASSOCIAÇÃO BRASILEIRA DE NORMAS}

TÉCNICAS. NBR 9202: cimento portland e outros materiais em pó: determinação da finura por meio da peneira $0,044 \mathrm{~mm}\left(\mathrm{n}^{\circ} 325\right)$ - Método de ensaio. Rio de Janeiro, 1985.

\section{ASSOCIAÇÃO BRASILEIRA DE NORMAS}

TÉCNICAS. NBR 11579: cimento portland: determinação da finura por meio da peneira $75 \mu \mathrm{m}$ $\left(\mathrm{n}^{\circ} 200\right)$ - Método de ensaio. Rio de Janeiro, 1991.

\section{ASSOCIAÇÃO BRASILEIRA DE NORMAS TÉCNICAS. NBR 12653: materiais pozolânicos.} Rio de Janeiro, 1992a. 
ASSOCIAÇÃO BRASILEIRA DE NORMAS TÉCNICAS. NBR 5752: Materiais pozolânicos: determinação de atividade pozolânica com imento Portland: índice de atividade pozolânica com cimento: método de ensaio. Rio de Janeiro, 1992b.

ASSOCIAÇÃO BRASILEIRA DE NORMAS TÉCNICAS. NBR 7215: cimento Portland: determinação da resistência à compressão. Rio de Janeiro, 1997.

\section{ASSOCIAÇÃO BRASILEIRA DE NORMAS}

TÉCNICAS. NBR NM 67: concreto:

determinação da consistência pelo abatimento do tronco de cone. Rio do Janeiro, 1998.

\section{ASSOCIAÇÃO BRASILEIRA DE NORMAS}

TÉCNICAS. NM 23: cimento Portland e outros materiais em pó: determinação da massa específica. Rio de Janeiro, 2000.

ASSOCIAÇÃO BRASILEIRA DE NORMAS TÉCNICAS. NBR NM 65: cimento Portland: determinação do tempo de pega. Rio de Janeiro, 2003a.

ASSOCIAÇÃO BRASILEIRA DE NORMAS TÉCNICAS. NBR NM 248: agregados: determinação da composição granulométrica. Rio de Janeiro, 2003b.

\section{ASSOCIAÇÃO BRASILEIRA DE NORMAS}

TÉCNICAS. NBR 9778: argamassa e concreto endurecido: determinação da absorção de água, índice de vazios e massa específica. Rio de Janeiro, 2005b.

\section{ASSOCIAÇÃO BRASILEIRA DE NORMAS} TÉCNICAS. NBR 5739: concreto: ensaios de compressão de corpos-de-prova cilíndricos. Rio de Janeiro, 2007.

ASSOCIAÇÃO BRASILEIRA DE NORMAS TÉCNICAS. NBR 5738: concreto: procedimento para moldagem e cura de corpos-de-prova. Rio de Janeiro, 2003.

\section{ASSOCIAÇÃO BRASILEIRA DE NORMAS}

TÉCNICAS. NBR 8522: concreto: determinação do módulo estático de elasticidade à compressão. Rio de Janeiro, 2008.

\section{ASSOCIAÇÃO BRASILEIRA DE NORMAS} TÉCNICAS. NBR NM 52: agregado miúdo: determinação da massa específica e massa específica aparente. Rio de Janeiro, 2009a.

\section{ASSOCIAÇÃO BRASILEIRA DE NORMAS} TÉCNICAS. NBR NM 53: agregado graúdo: determinação da massa específica, massa específica aparente e absorção de água. Rio de Janeiro, 2009b.
ASSOCIAÇÃO NACIONAL DA INDÚSTRIA CERÂMICA. Diagnóstico da Indústria de Cerâmica Vermelha no Estado do Rio de Janeiro. 2005a. Disponível em: <www.anicer.org.br>. Acesso em: 12 jun. 2012.

CARNEIRO, V. L.; MOURA, W. A.; LEITE, M. B. Influência do Uso de Resíduo de Cerâmica Vermelha e Finos de RCD Como Substituição Parcial de Cimento, Para Produção de Argamassas. In: ENCONTRO NACIONAL SOBRE APROVEITAMENTO DE RESÍDUOS NA CONSTRUÇÃO, Feira de Santana, 2009. Anais... Feira de Santana: UEFS, 2009.

CAVALCANTI, D. J. H. Contribuição ao Estudo de Propriedades do Concreto Auto-Adensável Visando Sua Aplicação em Elementos Estruturais. Maceió, 2006. Dissertação (Mestrado em Engenharia Civil) - Escola de Engenharia, Universidade Federal de Alagoas, Maceió, 2006.

DESIR, J. M. et al. Avaliação da Contribuição da Atividade Pozolânica do Resíduo de Tijolo Moído na Resistência de Argamassas. In: INTER AMERICAN CONFERENCE ON NONCONVENTIONAL MATERIALS AND TECHNOLOGIES IN ECOLOGICAL AND SUSTAINABLE CONSTRUCTION, Rio de Janeiro, 2005. Proceedings... Rio de Janeiro: Universidade Estadual Norte Fluminense, 2005.

DIAS, J. F. Avaliação de Resíduo da Fabricação de Telhas Cerâmicas Para Seu Emprego em Camadas de Pavimento de Baixo Custo. São Paulo, 2004. Tese (Doutorado em Engenharia Civil) - Escola Politécnica, Universidade de São Paulo, São Paulo, 2004.

HEIKAL, M.; ZOHDY, K. M.; ABDELKREEM, M. Mechanical, Microstructure and Rheological Characteristics of High Performance SelfCompacting Cement Pastes and Concrete Containing Ground Clay Bricks. Construction and Building Materials, v. 38, p. 101-109, jan. 2013.

JACKSON, P. J. Portland Cement: classification and manufacture. In: HEWLETT, P. Lea's Chemistry of Cement and Concrete. New York: Elsevier Science \& Technology Books, 2004. p. 24-94.

JOHN, V. M. Reciclagem de Resíduos na Construção Civil. São Paulo, 2000. Tese (Livre Docência) - Escola de Engenharia, Universidade de São Paulo, São Paulo, 2000. 
LINS, F. A. F. Panorama da Produção e Consumo de Rochas e Minerais Industriais no Brasil. In: CENTRO DE TECNOLOGIA MINERAL; Ministério da Ciência e Tecnologia (Coord.). Rochas \& Minerais Industriais: usos e especificações. Rio de Janeiro: CETEM, 2005. p. 11-29.

MARTINS NETO, A. A. A.; DJANIKIAN, J. G. BT/PCC/235: aspectos de desempenho da argamassa dosada em central. Boletim Técnico da Escola Politécnica da USP, São Paulo, 1999.

MEHTA, P. K.; MONTEIRO, P. J. M. Concreto: microestrutura, propriedades e materiais. São Paulo: Ibracon, 2008.

PEREIRA-DE-OLIVEIRA, L. A.; CASTROGOMES, J. P.; SANTOS, M. S. S. The Potential Pozzolanic Activity of Glass and Red-Clay Ceramic Waste as Cement Mortars Componentes. Construction and Building Materials, v. 31, p. 197-203, 2012.
RODRIGUES, P. P. F. ET-67 Parâmetros de Dosagem do Concreto. 2. ed. São Paulo. ABCP, 1995.

SENTHAMARAI, R. M.; MONAHARAN, P. D. Concrete With Ceramic Waste Aggregate. Cement \& Concrete Composites, v. 37, p. 910-913, 2005.

TUTIKIAN, B. F.; DAL MOLIN, D. Concreto Auto-Adensável. São Paulo: PINI, 2008.

VIEIRA, C. M. F.; SOUZA, E. T. A.;

MONTEIRO, S. N. Efeito da Incorporação de Chamote no Processamento e Microestrutura da Cerâmica Vermelha. Cerâmica, v. 50, n. 315, p. 254-260, 2004.

VIEIRA, A. A. P. Estudo do Aproveitamento de Resíduos de Cerâmica Vermelha Como Substituição Pozolânica em Argamassas e Concretos. João Pessoa, 2005. Dissertação (Mestrado em Engenharia Civil) - Escola de Engenharia, Universidade Federal da Paraíba, João Pessoa, 2005.

Departamento de Engenharia Civil, Centro de Ciências Exatas e Tecnologia | Universidade Federal de Sergipe | Cidade Universitária, Prof José Aloísio de Campos, Rosa Elze | São Cristovão - SE - Brasil | CEP 49100-000 | Tel.: (79) 2105-6700 | E-mail: angelasales19@gmail.com

Ricardo dos Santos Alferes Filho

Departamento de Engenharia Civil, Centro de Ciências Exatas e Tecnologia | Universidade Federal de Sergipe | Email: ricardo_alferes@hotmail.com

Revista Ambiente Construído

Associação Nacional de Tecnologia do Ambiente Construído

Av. Osvaldo Aranha, $99-3^{\circ}$ andar, Centro

Porto Alegre - RS - Brasil

CEP $90035-190$

Telefone: +55 (51) 3308-4084

Fax: +55 (51) 3308-4054

www.seer.ufrgs.br/ambienteconstruido

E-mail: ambienteconstruido@ufrgs.br 